\title{
Early Detection Coronavirus Transmission on Object Surfaces using Kite Bones Method
}

\author{
Julianus Gesuri Daud \\ Dept. Electrical Engineering \\ Manada State Polytechnic \\ Manado, Indonesia
}

\author{
Muchdar Dg. Patabo \\ Dept. Electrical Engineering \\ Manada State Polytechnic \\ Manado, Indonesia
}

\author{
Josephine Sundah \\ Dept. Electrical Engineering \\ Manada State Polytechnic \\ Manado, Indonesia
}

\begin{abstract}
COVID-19 can be passed from person to person through droplets that come out of the nose or mouth of an infected person when they sneeze. Even droplets can fall on objects and surfaces around us. By using the "kite bone" method which emphasizes the element of balance, early detection of corona virus transmission before students do practicum at the Distribution, Protection and Energy Conversion Laboratory will be able to prevent the spread of the corona virus to humans and equipment made of metal and non-metal. The laboratory equipment prototype placed at the door provided stimulation to each student where their bodies were illuminated with incandescent lamps for 3 minutes to 5 minutes with the result that $42.1 \%$ felt more confident, $21 \%$ felt healthy, $15.8 \%$ felt excited and $10,5 \%$ each feel comfortable and happy so that practicum activities in the laboratory run smoothly.
\end{abstract}

\section{General Terms}

Covid-19, Safety.

\section{Keywords}

Coronavirus transmission, kite bones method, heater corona.

\section{INTRODUCTION}

In 2003, a study was conducted which later revealed that the cause of severe acute respiratory syndrome (SAFE) or severe acute respiratory syndrome has been identified as a new coronavirus called SAFE-rcoV. By using the bioinformatic method, a detailed domain search has been carried out to determine the replication process of this virus [1]. Year 2004 using a heuristic algorithm for assembling DNA sequences. The computational experiment shows how the speed of a parallel algorithm depends on a number of processes. Tests from the trials with the coronavirus show a biological development [2]. The cause of severe acute respiratory syndrome (SARS) has been identified as the new coronavirus $(\mathrm{CoV})$ [3]. These variations reflect the evolution of the SARS virus in the human population. It has been demonstrated in a recent real case in Guang Dong, China for the detection of SARS-CoV [4]. Then a study on the phase detection of a twowave flexural plate wave (FPW) sensor was carried out to design and integrate a miniature system and provide a comprehensive methodology for portable use in biosensor applications in the acute respiratory syndrome coronavirus (SARS-CoV) [5]. Since the outbreak of severe acute respiratory syndrome (SARS) occurred in China and the first cases appeared in mid-November 2002. The etiological agent of this disease was discovered to be a previously unknown coronavirus, SARS-CoV. The detailed pathology of SARS$\mathrm{CoV}$ infection and the host response to viral infection is still unknown [6]. Severe acute respiratory syndrome (SARS) is a new human respiratory infection caused by the SARS coronavirus (SARS-CoV). This virus uses spike protein (S) to interact with the angiotensin 2 converting enzyme, the host cell receptor [7]. Some of these hosts provide many avenues for disease to occur. In particular, the SIS and SIR epidemic models were formulated for pathogens that can infect $n$ different hosts. The basic reproductive number is counted and is shown to increase with $\mathrm{n}$, the number of hosts that can be infected. Therefore, the likelihood of disease occurring increases with the number of infected hosts [8]. Research on the detection of acute respiratory syndrome acute coronavirus nucleocapsid protein (SARS) in human serum has been demonstrated [9]. The structure of the nucleotide composition of the SARS Corona virus which is the cause of SARS was analyzed [10]. Viral multiplication in cell culture is monitored and examined under a transmission electron microscope [11]. It is known that severe acute respiratory syndrome (SARS) is a serious form of pneumonia that causes acute respiratory distress and sometimes death. So in this study, a strong and potential vaccine is investigated which can be optimized against SARS and which has a high chance of successful immunization and has a higher probability of fighting this terrible disease [14]. In this study, we collected 141 MERS$\mathrm{CoV}$ coding sequences from the National Center for Biotechnology and Information (NCBI), including sequences isolated in Korea in 2015. Phylogenetic analysis was carried out using the method. Maximum Likelihood for checking the overall pattern of variation among target sequences, and then dividing the target sequence into 4 different groups according to the country occurring and the host species. The results show that the order of Korean origin has very small differences with that collected from Saudi Arabia in 2015, whereas the other groups collected from the United States and the UK in 2013 and 2014 show more complicated differences. We also compared sequences from Korea with sequences from camel origin, and it was found that the substitution patterns were somewhat different from those of human viruses [15]. In 2015 an outbreak of Middle East Respiratory Syndrome (MERS) has occurred in South Korea. Mathematical modeling was carried out with epidemic curve data obtained from the outbreak [16]. Empirical study of Middle East Respiratory Syndrome is a respiratory disease spread by the MERS Coronavirus, which first occurred in the Kingdom of Saudi Arabia in 2017. MERS-CoV is a respiratory disease that is spreading worldwide. As the need for a diagnostic system that accurately predicts MERS-CoV infection has increased, exploiting the performance of classifier models of various classifications can greatly help improve the predictive accuracy of MERS-CoV infection. By collecting MERS-CoV amino acid sequences from 15 different regions, the analysis was performed using a Neural Network and Support Vector Machine. The use of artificial intelligence algorithms can differentiate each virus and find out the route of transmission, a common feature of detected 
sequences [17], [18]. The Middle East respiratory coronavirus syndrome (MERS-CoV) outbreak in South Korea in April 2015 resulted in 186 infections and 37 deaths by the end of October 2015. MERS-CoV was isolated from imported patients in China. The envelope (E) protein, a small structural protein MERS-CoV, plays an important role in host recognition and infection. Using the bioinformatics method, we analyzed the MERS-CoV genome sequence and identified a potential B-cell epitope of the $\mathrm{E}$ protein, which might significantly increase the flow of MERS vaccine development [19]. The 2019 novel virus outbreak (2019-nCoV) has been treated as a Public Health Emergency for International Concern by the World Health Organization. This work made an early prediction of the 2019-nCoV outbreak in China based on a simple mathematical model and limited epidemiological data. Combing the characteristics of historical epidemics, this study found that part of the data released did not make sense. Putting the implausible data aside, the prediction model suggests that the cumulative number of 2019-nCoV cases could reach 76,000 to 230,000 , with a peak of unrecovered infections $(22,000-74,000)$ occurring in late February 2020 to early March 2020. After that, cases of unrecovered infections will rapidly decline in monotony until early May to late June 2020, when the 2019-nCoV outbreak will fade. Strong antiepidemics can reduce $40 \%-49 \%$ of the cumulative cases infected. Improved medical care could also lead to about half the reduction in transmission and effectively shorten the duration of 2019-nCoV [20]. In Indonesia, it was confirmed that there were 69 initial patients who were treated positive for the corona virus based on existing data up to March 13, 2020 [21]. Of these 12 people are under 29 years of age. Then on March 14, 2020 someone was detected as patient 01 in North Sulawesi [22]. Based on these literature reviews, anticipatory steps will be taken to break the chain of the spread of coronavirus through research on "Early detection of coronavirus transmission on surfaces using the kite bones method" at the Energy Conversion, Distribution and Protection Laboratory.

\section{KITE BONES METHOD}

Using the kite bone or "kite bone" method [23] as shown in Figure 1, the main bones (upper bone, lower bone) and shoulder bones (Right-R, Left-L) were prepared in advance. Before being tied together, an even distribution is done where the thread is tied as a midpoint between the two sides of the kite bones. To ensure the point of balance is reached in the midbone, the position of the thread is slowly shifted to the left and right in figure 1 (a). When the equilibrium point of both sides is reached, the two halves of the kite, both the main bone and the shoulder blades, are tied together (the midpoint) as shown in Figure 1 (b). In this position, the thread is tied at all four ends, each starting from the end of the lower bone point to the end of point $\mathrm{L}$ and from the end of the lower bone point to the end of point $\mathrm{R}$. Then from the top right end of the shoulder end is connected to the end of the upper bone and left shoulder is connected to the end of the L bone and tied with thread. To make a kite, the joints of the kite are glued together with special paper.

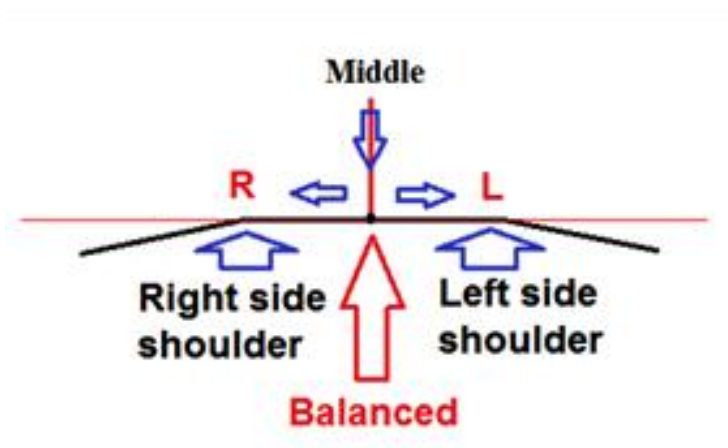

(a)

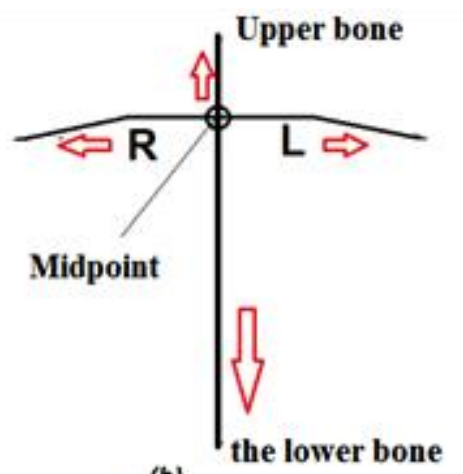

(b)

Fig 1: Kite bone method

In Figure 2, if the surface of the object is made of metal or glass or aluminum, if a foreign object sticks, such as a droplet ( $x$ factor) from someone infected with the coronavirus, it will not affect the structure of the object, but the liquid remains in the area where the droplet falls. It is the same with someone when he is infected, but because he has good stamina, he still looks healthy or is categorized as a person without symptoms.

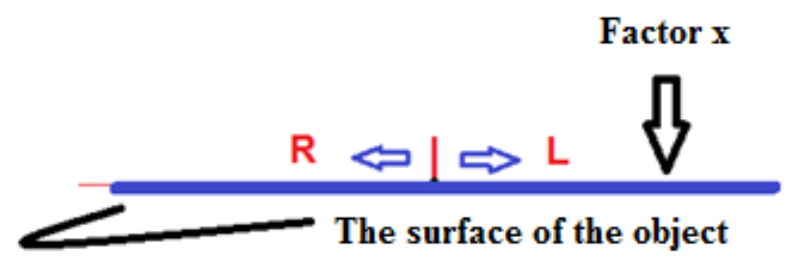

Fig 2: Foreign objects fall on the surface of the object

But on the contrary, as shown in Figure 3, if the surface of the object is made of paper, for example hvs paper, newsprint or even hair, the droplets will blend with the existing objects so that there is an imbalance in the object due to structural changes in the object. People infected with the corona virus will experience an imbalance in their body structure. As with the kite bones method, the imbalance is indicated by the displacement of the L or Left (left) side where the kite bone is longer in size than the $\mathrm{R}$ side. Figure 3 below shows the $\mathrm{L}$ position pressed down while the $\mathrm{R}$ position is raised upwards. 
In this study, one indication that someone might be exposed to the Corona virus is a body temperature above $37.3{ }^{\circ} \mathrm{C}$.

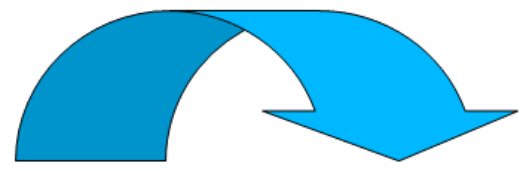

Imbalance occurs

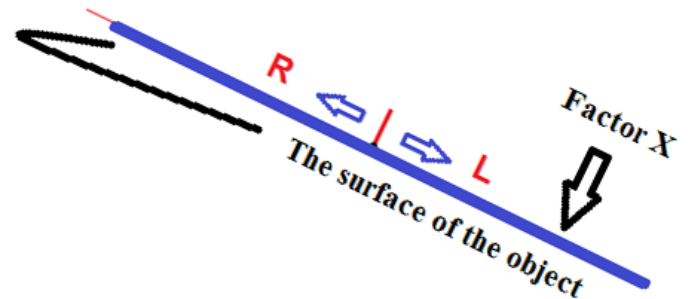

Fig 3: There was a change in structure

\section{PROTOTYPE LABORATORY}

\subsection{Survey Data}

A survey was conducted in several places including the supermarket Jumbo Supermarket as shown in Figure 4. If we look closely, the transmission of Covid -19 can only be through saliva (droplets), not through the air (airborne). Of course human saliva or saliva. Has not been found to be transmitted from the saliva of dogs, cats or other pets. Only from human saliva. Technically, the saliva gushes (spurts), then the splashes enter the nostrils, mouths and eyes of other people, or stick to the surfaces of objects around them, when people with the corona virus speak, yawn, cough, sneeze or spit. This corona virus likes to nest in cold areas, and is always wet and in dark places. The most ideal place in the human body for the growth and development of the corona virus, which fulfills the three elements above, is the throat [24]. When a person is indicated by corona and when he speaks, yawns, coughs or sneezes, there is air pressure from the body that comes out through the throat, grabs the throat wall and carries the virus, mingled with saliva gushing out. Saliva filled with the corona virus will stick to other people's faces such as the nostrils, mouth or eyes of that person or

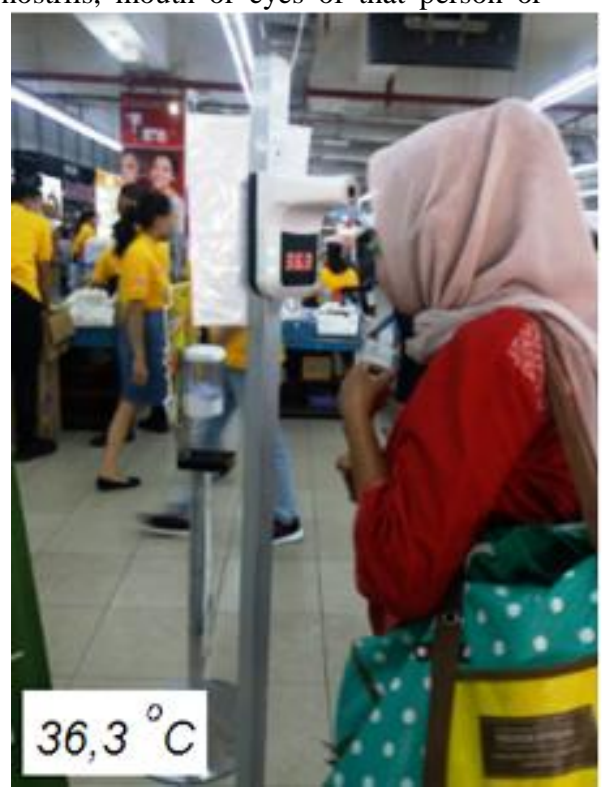

various solid surfaces such as tables, walls, glass, doors, door handles and may stick to our clothes or other people's clothes too on iron fences, car surfaces and many other surfaces of innumerable solid objects.

\subsection{Prototype Design}

It is not yet known exactly how long COVID-19 can last on the surface of an object, although early studies show that COVID-19 can last up to several hours, depending on the type of surface, temperature or humidity of the environment. With the assumption that coronavirus transmission occurs in cold, wet and dark conditions, a prototype is designed with an inverted concept from the three conditions so that if in cold air it speeds up the process of virus transmission because human factors can also contribute to the spread of influenza during winter because of more time can be spent indoors, maybe in a closer relationship with other people then in hot areas (hot) the opposite happens, namely the virus will not develop. Likewise, in wet situations and environments, the virus will last a long time, but if there is a dry environment, the virus will not be free to develop. In a dark place the virus can develop, otherwise in a bright place, the virus cannot develop.

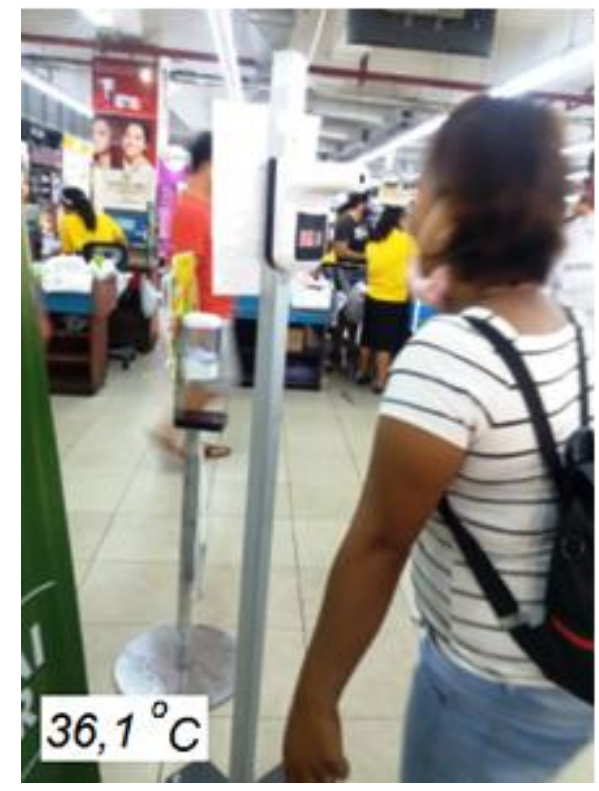

Fig 4: Check the temperature at Jumbo Supermarkets 
Based on the above concept, an equipment design called "Heater Corona" was carried out in the form of a rectangular box with a height of $220 \mathrm{~cm}$ or $2.20 \mathrm{~m}$ and a width of $110 \mathrm{~cm}$ $(1.1 \mathrm{~m})$ and a width of $33 \mathrm{~cm} .10$ pieces of 100 watt incandescent lamps are given in the box so that the total when

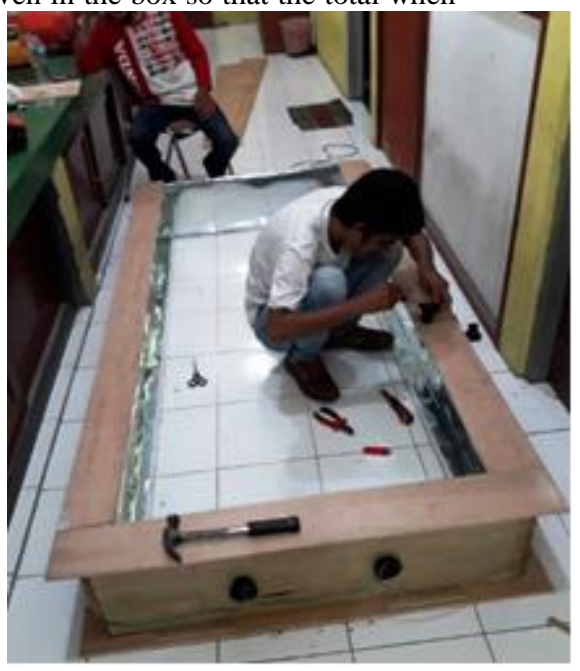

turned on has 1000 watts of power. The left side is 4 lamps (4 $\mathrm{x} 100$ watts) as well as the right side consists of 4 lamps (4 x 100 watts) while from above it is given 2 lamps ( 2 x 100 watts). Look at picture 5 .

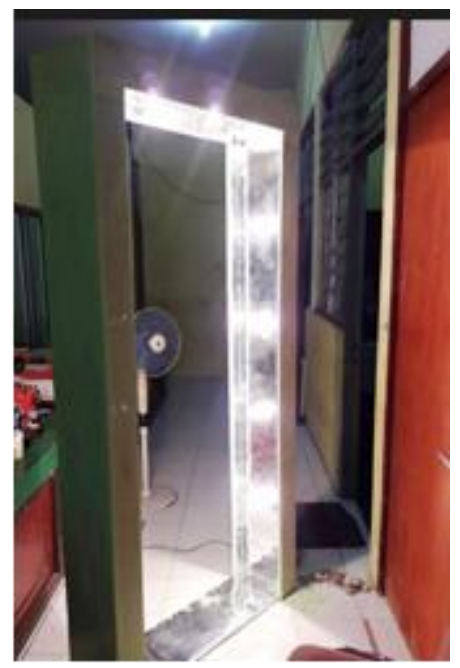

Fig 5: Making Laboratory Prototypes

To fulfill the provisions of the Covid-19 Task Force because students are not allowed to gather in large numbers and they are divided into small groups or 2 people who will occupy each one practice table. As for the physical condition of these students, it is not certain whether any of them have contracted Covid-19 or are categorized as people without symptoms. So if the person concerned talks, yawns, coughs, sneezes or spits, then the bursts of the corona virus in the saliva and originating from the human throat will have the potential to stick to many kinds of objects including parts of a person's body, including hands, hair, face and clothes or student practical suits including pens, books, bags and others. The technique can vary, but in principle, the saliva with the charge of corona is transferred directly from the sufferer to the eyes, nostrils and mouths of other healthy people, anywhere, anytime and in whatever situation is possible.

\section{TEST RESULT}

The stages of practicum activities are carried out in several steps: Step 1: Students use a mask and wash their hands first in the space provided (Figure 6).
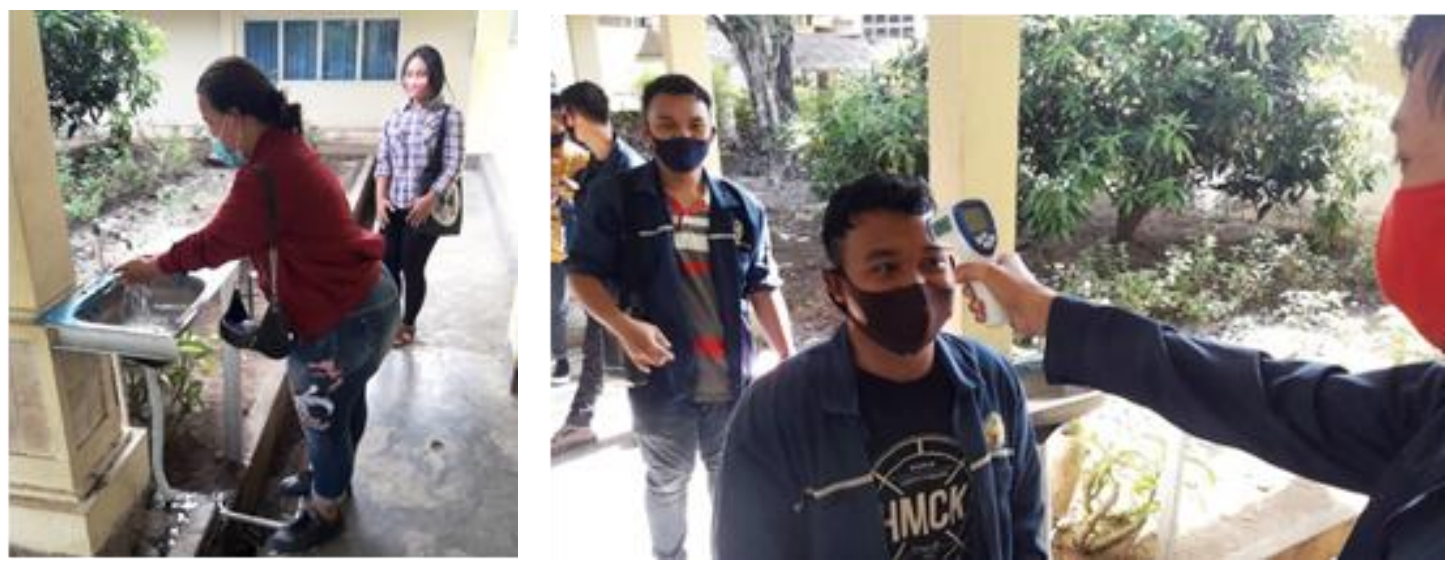

Fig 6: Hand washing and measuring temperature

Students occupy the queue according to serial number 1 to serial number 6 on the first shift. Step 2, one by one, they take turns in order to have their body temperature measured which is given a limit of below $37.5{ }^{\circ} \mathrm{C}$. If you find someone who has a body temperature exceeding this value, the student concerned is not allowed to enter. Step 3 is an important stage because this is where the students will be warmed through the "corona heater" in a way that when they enter the box, the door is closed and for 2- 3 minutes. In a standing position and facing forward. The incandescent lights on the left, right, above are all turned on, including the dry air that is blown from the fan so that it makes things hot, dry and bright as opposed to the concept of cold, wet and dark. Step 4 Students follow practicum procedures according to practical jobs. Step 5 Students wash their hands before leaving the laboratory practicum room. Based on body temperature measurement data as shown in Figure 6 and the results are shown in table 1, it was recorded that 19 students in semester V class 5 TL2 Study Program D4 Electrical Engineering were all still in normal body temperature conditions or below $<36.8{ }^{0} \mathrm{C}$. There were 6 students with a temperature of $36.5{ }^{0} \mathrm{C}$ so that they were allowed to enter through the designated door to take 
part in the practicum after going through the corona heater box. The lowest temperature was $36.1{ }^{\circ} \mathrm{C}$ and the highest was $36.8{ }^{\circ} \mathrm{C}$.

Table 1. Temperature of class 5 students TL2 D4

\begin{tabular}{|c|l|l|r|}
\hline Number & Temperature & $\begin{array}{l}\text { Number } \\
\text { of people }\end{array}$ & Percentage \\
\hline 1 & $36,8^{\circ} \mathrm{C}$ & 2 persons & $10.5 \%$ \\
\hline 2 & $36,7^{\circ} \mathrm{C}$ & 4 persons & $21 \%$ \\
\hline 3 & $36,6^{\circ} \mathrm{C}$ & 3 persons & $15.7 \%$ \\
\hline 4 & $36,5^{\circ} \mathrm{C}$ & 6 persons & $31.6 \%$ \\
\hline 5 & $36,4^{\circ} \mathrm{C}$ & 1 persons & $5.3 \%$ \\
\hline 6 & $36,3^{\circ} \mathrm{C}$ & 2 persons & $10.5 \%$ \\
\hline 7 & $36,1^{\circ} \mathrm{C}$ & 1 persons & $5.3 \%$ \\
\hline
\end{tabular}

So far, many people think that the normal human temperature is at 37 degrees Celsius. In fact, the normal temperature of humans is in the range of 36.5 - 37.2 degrees Celsius. Please also note that the normal human body temperature can change over time, the temperature can be higher or lower. This is proven when measurements are made for 5th semester students of class 5 TL1 D3 Electrical Engineering Program. There is one person who has a body temperature of $37.4{ }^{\circ} \mathrm{C}$. The student is then asked to walk out of the room to breathe fresh air around the campus and within 15 minutes then check the temperature again. The body temperature check value decreased from $37.4{ }^{\circ} \mathrm{C}$ to $37.0{ }^{\circ} \mathrm{C}$ so it can be said that the body temperature is always changing (table 2 ).

Table 2. Temperature of class 5 students TL1 D3

\begin{tabular}{|c|l|l|r|}
\hline Number & Temperature & $\begin{array}{l}\text { Number of } \\
\text { people }\end{array}$ & Percentage \\
\hline 1 & $37,4^{\circ} \mathrm{C}$ & 1 persons & $4.2 \%$ \\
\hline 2 & $37,0^{\circ} \mathrm{C}$ & 1 persons & $4.2 \%$ \\
\hline 3 & $36,9^{\circ} \mathrm{C}$ & 2 persons & $8.3 \%$ \\
\hline 4 & $36,8^{\circ} \mathrm{C}$ & 2 persons & $8.3 \%$ \\
\hline 5 & $36,7^{\circ} \mathrm{C}$ & 4 persons & $16.7 \%$ \\
\hline 6 & $36,6^{\circ} \mathrm{C}$ & 3 persons & $12.5 \%$ \\
\hline 7 & $36,5^{\circ} \mathrm{C}$ & 4 persons & $16.7 \%$ \\
\hline 8 & $36,3^{\circ} \mathrm{C}$ & 6 persons & $25 \%$ \\
\hline 9 & $36,2^{\circ} \mathrm{C}$ & 1 persons & $4.2 \%$ \\
\hline
\end{tabular}

Of the 24 students, the temperature of $36.3{ }^{\circ} \mathrm{C}$ was the highest in the 6 students who had their body temperature checked with a percentage of $25 \%$.

Feeling comfortable, confident, excited are examples of expressions that radiate as long as students are in the box shown in Figure 7. Before entering the "corona heater" box, there were mixed feelings of students who were worried, afraid, anxious, unsettled and confused. However, after undergoing the heating process with a 1000 watt incandescent light bulb that provides bright light and emits hot rays, which over time increases in temperature and is evenly distributed in the box because there is a gust of dry air coming from the fan. The air that is formed turns into hot, dry and bright.

Table 3. Laboratory prototype test results

\begin{tabular}{|c|l|l|r|}
\hline Number & \multicolumn{2}{|l|}{ Feeling after warming up } & Percentage \\
\hline 1 & Feel comfortable & 2 persons & $10.5 \%$ \\
\hline 2 & Happy & 2 persons & $10.5 \%$ \\
\hline 3 & $\begin{array}{l}\text { Feel more } \\
\text { confident }\end{array}$ & 8 persons & $42.1 \%$ \\
\hline 4 & Feel healthy & 4 persons & $21.1 \%$ \\
\hline 5 & Feeling excited & 3 persons & $15.8 \%$ \\
\hline Total & 19 persons & $100 \%$ \\
\hline
\end{tabular}

This concept is contrary to the potential for the development of the corona virus, namely in cold, wet and dark conditions. With a time of 3 minutes to 5 minutes it will feel enough to dry the droplets attached to the face, hands and clothes besides giving a stimulus to every student where their bodies will feel warm. It was recorded that there were 8 students or $42.1 \%$ of whom felt more confident, then $21 \%$ of their bodies felt healthy, $15.8 \%$ of students felt excited and $10.5 \%$ each felt comfortable and happy.

Table 3 shows the test results on 19 students who underwent testing after going through heating in the corona heater box. Practical activities in the laboratory run smoothly (Figure 8). 

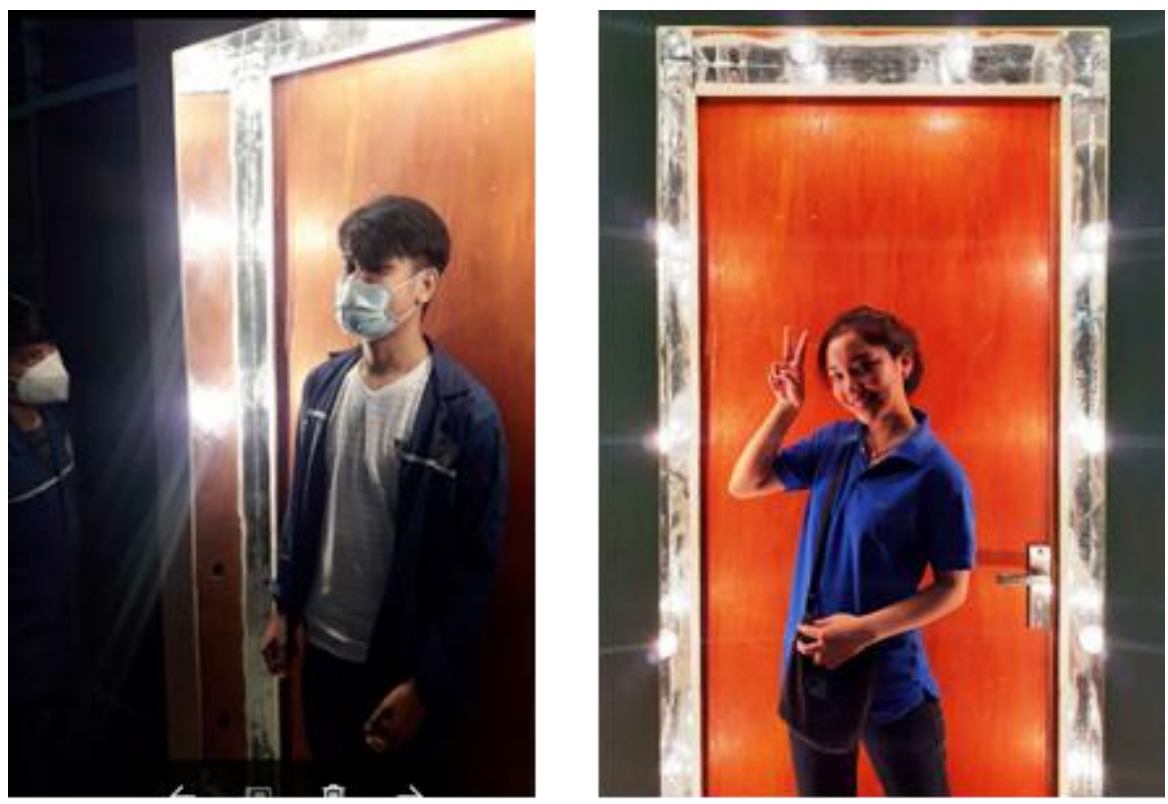

Fig 7: Students in corona heater box

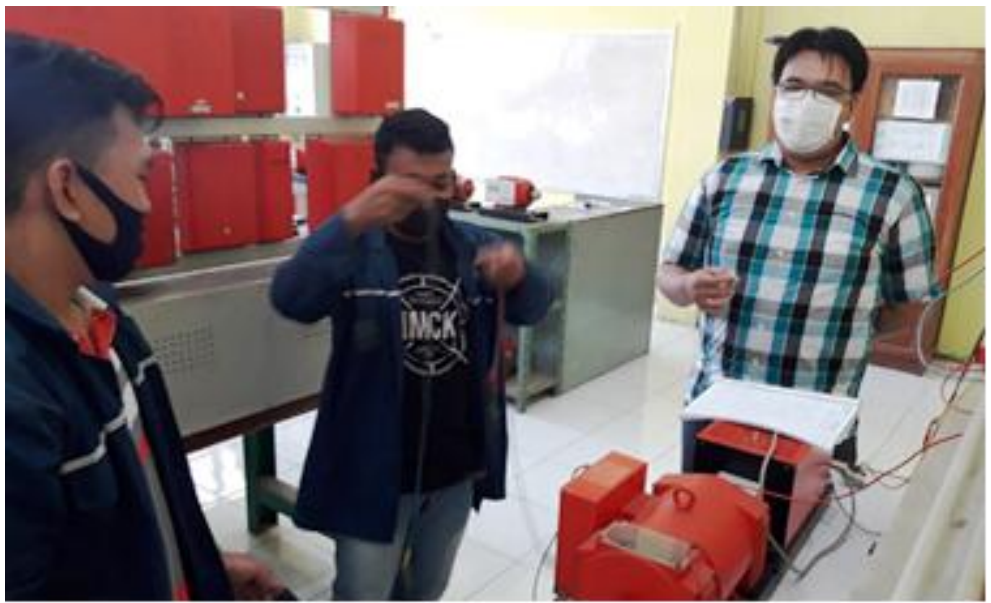

Fig 8: Students attend practicum

\section{CONCLUSION}

Student body temperature ranges from $36.1{ }^{\circ} \mathrm{C}$ to $37{ }^{\circ} \mathrm{C}$. There are students who have a body temperature of $37.4{ }^{\circ} \mathrm{C}$ but after re-examination within a span of 15 minutes, the body temperature drops to $37{ }^{\circ} \mathrm{C}$ meaning that a person's body temperature can always change. The temperature in the Corona Heater toolbox increases with time because the heat generated from the incandescent lamp makes it possible if there are droplets on the skin or practice coat it will dry quickly so that the ideal time ranges from 3 minutes to 5 minutes. The laboratory prototype equipment provides a stimulus for each student to become more confident, feel healthy, comfortable and happy so that practicum activities in the laboratory run smoothly. Several things need to be considered. Warm-up time in the box should not be more than 10 minutes and the size of the box can be made wider so that it can accommodate students whose body weight is large.

\section{ACKNOWLEDGMENTS}

Thank you to the Head of the Manado State Polytechnic Research and Community Service Center for sponsoring this activity

\section{REFERENCES}

[1] Xin'gang Zhao, Han Jingdong, Ning Yuanheng, Meng Anming, Chen Yeguang, 2003, "Bioinformatic analysis of putative gene products encoded in SARS-HCoV genome." Tsinghua Science nd Technology. Volume 8..

[2] J. Blazewicz, M. Figlerowicz, p. Jackowiak, D. Janny, D. Jarczynski, M. Kasprzak, M. Nalewaj, B. Nowierski, R. Styszynski, L. Szajkowski, P. Widera, 2004, “ Parallel DNA sequence assembly." Proceedings of the Fifth Mexican International Conference in Computer Science.

[3] Xinglai Ji, Shuqun Liu, Jesse Li-Ling, Zhirong Sun, 2004, " Protein subcellular localization prediction and genomic polymorphism analysis of the SARS coronavirus." Tsinghua Science and Technology. Volume 9.

[4] Lei Gao, Yongsheng Ding, Hua Dai, Zhende Huang, Shihuang Shao, 2004, " A novel fingerprint map of SARS-CoV with visualization analysis.." Third International Conference on Image and Graphics (ICIG'04).

[5] Wen-Yang Chang, Po-Hsun Sung, Chun-Hsun Chu, 
Ching-Jui Shih, Yu-Cheng Lin, 2008, " Phase Detection of the Two-Port FPW Sensor for Biosensing." IEEE Sensors Journal.

[6] M. M. Y. Waye, P. T. W. Law, Chi-Hang Wong, T. C. C. Au, C. Chuck, Siu-Kai Kong, P. K. S. Chan, Ka-Fai To, A. W. I. Lo, J. Y. W. Chan, Yick-Keung Suen, H. Y. E. Chan, Kwok-Pui Fung, J. J. Y. Sung, Y. M. D. Lo, S. K. W. Tsui, 2005, " The 3a Protein of SARS-coronavirus Induces Apoptosis in Vero E6 Cells.” IEEE Engineering in Medicine and Biology 27 th Annual Conference.

[7] Kuo-Yuan Hwa, Wan Man Lin, Yung-I Hou, Trai-Ming Yeh, 2007, " Molecular Mimicry between SARS Coronavirus Spike Protein and Human Protein." Frontiers in the Convergence of Bioscience and Information Technologies.

[8] Robert K. McCormack, Linda J. S. Allen, 2007, “ Disease emergence in multi-host epidemic models." Mathematical Medicine and Biology. A Jounal of the IMA, Volume 24.

[9] Ying-Feng Chang, Jason C. Huang. Li-Chen Su, YiMing Arthur Chen, Chii-Chang Chen, Chien Chou, 2009, "Localized surface plasmon coupied fluorescence fiberoptic biosensor for severe acute respiratory syndrome coronavirus nucleocapsid protein detection. " $14^{\text {th }}$ OptoElectronics and Communications Conference.

[10] Francis Thamburaj, Copinath Ganapathy, 2010, “ Analysis of genome signature strength of SARS coronavirus using Self-Organizing Map neural network. “ International Conference on Communication and Computational Intellingence (INCOCCI).

[11] Amer Alazawy, Siti-Suri Arshad, Mohd-Hair Bejo, Abdul-Rahman Omar, Tengku-Azmi Tengku Ibrahim, Saeed Sharif, Faruku Bande, Kamarudin Awang-Isa, 2011, "Ultrastructure of Felis catus whole fetus (Fcwf-4) cell culture following infection with feline coronavirus." IEEE.

[12] You-Ren Hsu, Geng-Yen Lee, Jen-Inn Chyi, Chung-ke Chang, Chih-Cheng Huang, Chen-Pin Hsu, Tai-Huang Huang, Fan Ren, Yu-Lin Wang, 2012, “ Investigation of the binding affinity of C-terminal domain of SARS coronavirus nucleocapsid protein to nucleotide using AIGAN/GaN high electron mobility transistors." SENSORS, 2012 IEEE.

[13] Yingxin Hu, Zhaohui Qi, Lijuan Zheng, Wenfeng Zhou, 2013, "A simple method for phylogenetic analysis of DNA sequences." Proceedings of 20133 rd International Conference on Computer Science and Network Technology.
[14] Amit Kumar, Anupam Bhattacharya, Amita Kashyap, 2013, " Antigenic epitope prediction of small envelope protein and designing a vaccine by using reverse vaccinology approach against SARS coronavirus Tor2 strain." 15 th International Conference on Advanced Computing Technologies (ICACT).

[15] Insung Ahn, Jin-Hwa Jang, 2015, "Comparative study of Middle East respiratory syndrome coronavirus using bioinformatics techniques." IEEE International Conference on Bioinformatics and Biomedicine (BIBM).

[16] Hyuk-Jun Chang, 2016, "Evaluation of the basic reproduction number of MERS-CoV during the 2015 outbreak in South Korea." 16 th International Conference on Control, Automation and Systems (ICCAS).

[17] Heba Kurdia, Nora AlMansour, 2017, "Identifying accurate classifier models for a text-based MERS-CoV dataset." Intelligent Systems Conference (IntelliSys).

[18] Soyoung Hong, Sungwoo Choi, Donghyun Kim, Taeseon Yoon, 2017, "Epidemiological analysis of MERS-CoV using NN and SVM in respect to applicability of AI in multiple classes." 19 th International Conference on Advanced Communication Technology (ICACT).

[19] Qian Xia, Xiaoyan He, Fangji Yang, Xuling Liu, Ying $\mathrm{Li}$, Yujing Liu, ZhengMeng Yang, Jianhai Yu, Bao Zhang, Wei Zhao, 2018, "Analysis of the Genome Sequence and Prediction of B-Cell Epitopes of the Envelope Protein of Middle East Respiratory Syndrome Coronavirus." IEEE/ACM Transactions on Computational Biology and Bioinformatics.

[20] Linhao Zhong, Lin Mu, Jing Li, Jiaying Wang, Zhe Yin, Darong Liu, 2020, "Early Prediction of the 2019 Novel Coronavirus Outbreak In the Mainland China Based on Simple Mathematical Model.” IEEE Access. Volume 8.

[21] Ministry of Health of the Republic of Indonesia, 2020, "Distribution of Corona Virus Patients by age in Indonesia." Jakarta.

[22] North Sulawesi Covid-19 Task Force, 2020, "Info on Covid-19 Patients in North Sulawesi." Manado.

[23] Julianus G. Daud, Fransiscus Tulung, Moody Tumembouw, 2018, "Solution to electricity problems in North Sulawesi through the utilization of Tidal Energy using the kite bones method with IoT." IEEE.

[24] https://www.tagar.id/proses-penularan-langsung-dan-taklangsung-virus-corona. 